\title{
Leisure time physical activity in 9- to 11-year-old children born moderately preterm: a cohort study
}

\author{
M. Nordvall-Lassen ${ }^{*}$, H. K. Hegaard ${ }^{1,2,3,4}$, C. Obel ${ }^{5}$, M. S. Lindhard ${ }^{6}$, M. Hedegaard ${ }^{3}$ and T. B. Henriksen ${ }^{6}$
}

\begin{abstract}
Background: Physical activity is one of the best documented activities with impacts on health in children and adults. Children born preterm show reduced physical and psychosocial function compared to children born at term. This may influence their level of physical activity. Reports on moderately preterm children's physical activities during childhood are limited. Thus, the aim of this study was to compare the leisure time physical activity at age 911 years of moderately preterm children with that of children born at term.

Methods: Data from 4941 mother-child pairs from the Aarhus Birth Cohort (1989-91) were used. The cohort gathered clinical information, including gestational age at delivery. Information about parental socio-demographic and lifestyle factors was obtained from questionnaires completed during the second trimester of pregnancy. Information about children's physical activities was reported in a 9- to 11-year follow-up questionnaire completed by parents detailing how many times per week their child participated in sports activities outside of school, hours spent per week playing outside, and hours per week engaged in sedentary activities. Data were analysed using multiple logistic regression with the lowest activity group as a reference group.
\end{abstract}

Results: A total of 158 children (3.2\%) were born moderately preterm, i.e., between 32 and 36 completed weeks. Children born moderately preterm participated in sports activities as often as their peers born at term; they also participated in frequent sports activities ( $\geq 4$ times per week) as often as their peers. There were no differences in hours per week spent playing outside or in sedentary activities between the two groups.

Conclusions: Nine- to 11-year-old moderately preterm children participated in sports activities outside school to a similar extent as their peers and engaged in outdoor activities and sedentary activities for the same duration of time per week as their peers born at term.

Keywords: Preterm birth, Leisure time physical activity, Moderately preterm, School age children

\section{Background}

Preterm delivery, defined as birth before 37 weeks of gestation [1], is strongly associated with neonatal morbidity and mortality [2] and with long-term sequelae [3-6]. Due to advances in neonatal intensive care, the survival of preterm children has increased considerably [7-10]. Preterm children are predisposed to difficulties with cognitive, behavioural, social, psychological, and motor functions [7, 11-16]; even moderately preterm (32-36 weeks)

\footnotetext{
* Correspondence: Nordvall_maria@hotmail.com

'The Research Unit of Women's and Children's Health, section 7821, The Juliane Marie Centre, Copenhagen University Hospital, Rigshospitalet, Blegdamsvej 9, DK-2100 Copenhagen, Denmark

Full list of author information is available at the end of the article
}

children are at an increased risk for developmental delay, neurologic impairments and learning problems $[17,18]$, which may contribute to difficulties participating in physical activities. Many studies have focused on these functional parameters, but little is known about normal everyday life functions, such as physical activity levels. Studies on adults with a birth weight of less than $1500 \mathrm{~g}$ have shown that they engage less frequently in leisure time physical activity $[19,20]$.

However, few studies have focused on physical activity in children born moderately preterm, even though this group makes up $80 \%$ of all premature births [17]. Physical inactivity is a risk factor for obesity, cardiovascular

(C) The Author(s). 2018 Open Access This article is distributed under the terms of the Creative Commons Attribution 4.0 International License (http://creativecommons.org/licenses/by/4.0/), which permits unrestricted use, distribution, and 
disease, type-2 diabetes, metabolic syndrome, and several other diseases [21, 22]. Adults born preterm have higher levels of risk factors for these diseases, such as high blood pressure [23], impaired glucose regulation $[24,25]$ and lower bone mineral density [26]. Cardiovascular disease risk factors have been reported to be reduced by regular physical activity, particularly in subjects with a low birth weight [27].

Research has shown that there is a life-trajectory of physical activity that begins early in life [28]. It is therefore important to investigate the level of physical activity in school-aged children who were born preterm without evident morbidity and who attend the same schools as children born at term. Do these children require special intervention to attain an adequate level of physical activity? Physical activity is quite possibly one of the best documented healthy activities for children [29]. The Danish National Board of Health has recommended a daily minimum of 60 min of moderate to high intensity physical activity and high intensity physical activity for a minimum $30 \mathrm{~min}$ at least three times a week for children [29].

Accordingly, we compared the leisure time physical activity of 9- to 11-year-old former moderately preterm children with their peers born at term using a birth cohort with a decade of follow-up. Moderately preterm delivery is defined as children born between 32 and 36 completed gestational weeks.

\section{Methods}

We used data from the Aarhus Birth Cohort. The cohort was established at the Department of Obstetrics at Aarhus University Hospital in August 1991 [30] The obstetrics department was the only maternity unit in the community of Aarhus and served a well-defined geographic area with a population of approximately 250,000 inhabitants. Antenatal care is free of charge in Denmark, and almost all (>97\%) women participated in the programme.

Briefly, all women attending routine antenatal care at Aarhus University Hospital in the period beginning in August 1989 and ending in September 1991 were invited to participate in the study. At enrolment, women at approximately 16 weeks' gestation were asked to complete a clinical questionnaire providing information about their medical and obstetrics histories, as well as information about their ages, heights, pre-pregnancy weights, levels of alcohol consumption, and smoking habits, as well as a second questionnaire (the research questionnaire) about socio-demographic characteristics and leisure time physical activities [31] The clinical questionnaire provided information included in each pregnant woman's obstetrical records. Following delivery, the attending midwife completed a structured birth registration form with information about the course of delivery and the condition of the newborn.

The present follow-up study is based on children from the cohort who were born between January 1990 and June 1992. During this period, 8643 women completed the clinical questionnaire, and 6782 women completed both questionnaires. Women who experienced foetal death $(n=2)$, delivered twins and triplets $(n=165)$ and delivered singletons without a valid gestational age $(n=15)$ were excluded, resulting in a study population of 6600 women.

In 2001, (January - December), the parents of these children were identified using the civil registration system [32], and they were invited to complete a parentadministered questionnaire concerning their child's behaviour, physical activity, health, and development. A total of 5147 questionnaires were returned. From this population we excluded children whose parents did not provide information on sports activities per week $(n=$ 78). Children with significant physical handicaps, chromosome abnormalities, autism, Asperger syndrome, cerebral palsy, mental retardation, severe chronic diseases, blindness, severe hearing loss and deafness, and severe heart defects were also excluded $(n=113)$ as well as children born before 32 completed gestational weeks $(n=15)$, leaving 4941 singleton infants born at term and moderately preterm, available for analysis.

\section{Exposure}

Moderately preterm delivery was defined as delivery between 32 and 36 completed gestational weeks. Gestational age was estimated by ultrasound measurements before 21 completed weeks of gestation in $86 \%$ of cases. In $8 \%$ of cases, gestational age was estimated using the date of a valid last menstrual period (LMP), corrected to a cycle length of 28 days: in $6 \%$, gestational age was estimated by the midwife using a less reliable LMP (primarily an LMP without information regarding specific cycle length) or ultrasound measurements taken after 21 weeks [33].

\section{Outcome}

Information regarding each child's leisure time physical activity level was obtained from the parent-administered questionnaires completed when each child was between 9 and 11 years of age. They were asked how many times per week their child participated in sports activities outside of school, how many hours a week after school their child was active outdoors, how many hours a week their child watched television, how many hours a week (in addition to schoolwork) their child read, including comic books, and how many hours a week (in addition to schoolwork) the child used a computer or played videogames. We created a category for children with very low physical activity levels whose parents reported that they did not participate in sports activities outside of school and engaged in fewer 
than four weekly hours of outdoor activities. The following characteristics were categorized as described in Table 1: whether the child's parents cohabited; maternal preexisting chronic maternal disease; maternal smoking before, during and after pregnancy; partner's smoking during and after pregnancy; maternal alcohol consumption during pregnancy; maternal leisure time physical activity during pregnancy; and parental education level.

The children's heights and weights were described by a mean and SD (standard deviation). The parents were asked if a medical doctor had ever diagnosed their child with asthma.

\section{Statistical analysis}

An initial Chi-square test for independence within contingency tables was used. Testing for trends and t-tests were carried out where appropriate. In a multivariate logistic regression analysis, the relation between preterm birth (gestational age, 32-36 completed weeks gestation vs. $\geq 37$ weeks gestation) and physical activity levels in children aged 9 to 11 was tested. A priori, we chose to include the following covariates in the analysis: maternal leisure time physical activity during pregnancy, maternal education level, paternal education level, maternal and paternal smoking habits after delivery, and the sex of the child, given previously demonstrated associations between preterm delivery as well as the child physical activity level $[19,34]$. We repeated all analyses in a sub analysis comparing the children born 32-36 weeks to those born 39-40 weeks. Furthermore, we repeated all analyses stratified by sex and after excluding children with asthma. We presented adjusted odds ratios with 95\% confidence intervals (CIs). Statistical significance was defined as a two-sided $P$ value less than 0.05 . We used SPSS 20.0 software (IBM) for all statistical analyses.

\section{Results}

Table 1 shows the proportion of children born moderately preterm and at term in relation to prenatal, parental and offspring characteristics at birth and 9 to 11 years later. In total, 158 infants (3.2\%) were born moderately preterm. Moderately preterm birth was associated with pre-existing maternal chronic diseases; maternal smoking before, during and after pregnancy; paternal smoking during pregnancy; less maternal leisure time physical activity during pregnancy and fewer years of parental education. Furthermore, children born moderately preterm had the same height and weight by ages 9 to 11 as children born at term. Children born moderately preterm had a higher frequency of asthma, as 19\% of moderately preterm children had asthma compared to $8.3 \%$ of children born at term (Table 1 ).

In our study population, $82 \%(n=4069)$ of children participated in sports outside of school on a weekly basis. Only $28 \%$ of school-aged children in our population participated in sports activities 3 times per week or more, as recommended by the national health guidelines for children [29]. More than half of the children reported participating in outdoor activities for more than $7 \mathrm{~h}$ a week. Eleven percent of the children reported participating in sedentary activities for $7 \mathrm{~h}$ or less per week. Less than half of the children reported participating in $15 \mathrm{~h}$ or more of sedentary activities per week (Table 2). No differences were observed between children born moderately preterm and children born at term.

The adjusted multivariate analysis showed that children born moderately preterm participated in sports activities as often as their peers born at term $(\mathrm{OR}=1.03$, 95\% CI (0.67-1.58)) and participated in sports activities 3 times per week and $\geq 4$ times per week as often as their peers born at term (Table 2). Similarly, children born moderately preterm played outside as often as their peers born at term. Furthermore, children born moderately preterm had the same level of very low physical activity as their peers born at term $(\mathrm{OR}=1.36$, 95\% (0.59-3.2)). Multiple logistic regression analyses showed that infants born moderately preterm participated in sedentary activity (watching television, using a computer, playing videogames, reading books and comics) as often as their peers born at term (Table 2). Sub-analyses showed similar results when we compared the children born moderately preterm with the children born in weeks 39-40.Additional sub-analyses showed that results were similar for boys and girls and that the results remained essentially unchanged after excluding 429 children diagnosed with asthma (data not shown).

\section{Discussion}

Due to the well-established higher risk of physical disadvantages, one may expect that children born preterm would be less leisure time physically active than their peers born at term. However, our data showed no differences in the activity levels of term and moderately preterm children aged 9 to 11 years. Parents of children born moderately preterm reported that their children were involved in leisure time sports activities to the same extent as children born at term. The same proportion of children in both groups followed the recommendation of high intensive physical activity by the Danish National Board of Health [29].

Additionally, there were no differences between children born moderately preterm and children born at term, considering hours spent participating in outdoor activities per week. Nor were there any differences in hours spent participating in sedentary activities-watching television, playing videogames, using a computer and reading. 
Table 1 Parental and offspring $(N=4941)$ characteristics at birth and 9-11 years after moderately preterm birth (32-36 completed weeks). The Aarhus Birth Cohort, Denmark 1989-2001

\begin{tabular}{|c|c|c|c|}
\hline & Moderately preterm birth $\mathrm{n}^{\mathrm{a}}(\%)$ & Term birth $\mathrm{n}(\%)$ & $p$-value \\
\hline Total & $158(3.2)$ & $4783(96.8)$ & \\
\hline \multicolumn{4}{|l|}{ Prenatal maternal and paternal factors } \\
\hline $\begin{array}{l}\text { Cohabiting } \\
\text { Missing data (67) }\end{array}$ & $151(96.2)$ & $4583(97.2)$ & 0.46 \\
\hline $\begin{array}{l}\text { Pre-existing chronic disease } \\
\text { Missing data (173) }\end{array}$ & $13(8.5)$ & $179(3.9)$ & 0.01 \\
\hline $\begin{array}{l}\text { Smoking before pregnancy } \\
\text { Missing data (11) }\end{array}$ & $85(53.8)$ & $1857(38.9)$ & $<0.001$ \\
\hline $\begin{array}{l}\text { Smoking during pregnancy } \\
\text { Missing data (96) }\end{array}$ & $66(42.3)$ & $1311(28.0)$ & $<0.001$ \\
\hline Partner smoking during pregnancy & $81(63.3)$ & $1875(47.5)$ & 0.001 \\
\hline
\end{tabular}

\section{Missing data (96)}

Alcohol during pregnancy (units per week)

$$
<1
$$

$1-2$

$3+$

Missing data (98)

Leisure time physical activity during pregnancy

Sedentary

Light activity

Moderate to heavy activity

Missing data (225)

Offspring at 9-11 years

Girl

Boy

Height, mean (SD)

Weight, median (min-max)

Missing data (0)

Asthma diagnosed by a medical doctor

Yes

No

Do not know

Missing data (0)

Maternal smoking after delivery Missing data (12)

Paternal smoking after delivery

Missing data (149)

Maternal professional education

No education (after secondary schools +/- high schools)

Currently studying

1-2 years of education (after secondary schools $+/-$ high schools)

3-4 years of education (after secondary schools +/- high schools)

$4+$ years of education (after secondary schools $+/-$ high schools) Missing data (40)

Paternal professional education

No education (after secondary schools +/- high schools)

Currently studying
$81(63.3)$

94 (59.9)

$43(27.4)$

$20(12.7)$

$80(52.6)$

$68(44.7)$

$4(2.6)$

$74(46.8)$

$84(53.2)$

$142(8.1)$

$35(7.3)$

$30(19)$

127 (80.4)

1 (0.6)

85 (53.8)

95 (61.3)

$12(7.6)$

$10(6.3)$

44 (27.8)

75 (47.5)

17 (10.8)

$1(0.7)$
0.52

2786 (59.5)

1287 (27.5)

$613(13.1)$

0.005

1867 (40.9)

2382 (52.2)

315 (6.9)

2379 (49.7)

2404 (50.3)

$142(8.0)$

0.74

$34.5(7.1)$

0.34

$<0.001$

399 (8.3)

4348 (90.9)

$36(0.8)$

1926 (40.6)

0.001

2063 (44.5)

$<0.001$

0.07

354 (7.5)

104 (2.2)

1295 (26.4)

2271 (47.9)

763 (16.1)

0.022
64 (1.4) 
Table 1 Parental and offspring $(N=4941)$ characteristics at birth and 9-11 years after moderately preterm birth (32-36 completed weeks). The Aarhus Birth Cohort, Denmark 1989-2001 (Continued)

\begin{tabular}{|c|c|c|c|}
\hline & Moderately preterm birth $\mathrm{n}^{\mathrm{a}}(\%)$ & Term birth $\mathrm{n}(\%)$ & $p$-value \\
\hline $1-2$ years of education (after secondary schools $+/-$ high schools) & $19(12.4)$ & $553(12.0)$ & \\
\hline 3-4 years of education (after secondary schools $+/-$ high schools) & 79 (51.6) & $2163(46.8)$ & \\
\hline $\begin{array}{l}4+\text { years of education (after secondary schools }+/ \text { - high schools) } \\
\text { Missing data (167) }\end{array}$ & $29(19.0)$ & $1354(29.3)$ & \\
\hline
\end{tabular}

${ }^{\mathrm{a}}$ Total differs due to missing values

Previous studies of physical activity and the exercise capacity of preterm children showed diverging results. Consistent with the results of our study, some studies of preschool- and school-aged children reported no differences in the levels of physical activity of preterm and term children [9, 35-37]. Other studies showed that young adults who were born preterm reported less exercise than control subjects [19, 38, 39]. This disparity may reflect real differences between the populations studied but may also be due to differences in the measurements of physical activity used for each of the studies. In our study, we measured each child's leisure time physical activity level based both on the frequency of sports activities per week and hours of outdoor activities per week, but we did not measure the performance level of each child.

Most previous studies included only children with very low birthweights $(1000-1500 \mathrm{~g})$ or extremely low birthweights $(<1000 \mathrm{~g})$ [9, 17-19, 35, 37, 38]. This may increase the likelihood of observing differences in the activity levels of children born preterm and children born at term due to the much higher overall

Table 2 Moderately preterm birth (32-36 completed weeks) and levels of sports activity, outdoor activity and sedentary activity at 911 years of age. The Aarhus Birth Cohort, Denmark 1989-1991, N = 4941

\begin{tabular}{|c|c|c|c|c|}
\hline & Moderately preterm birth $n$ (\%) 158 (3.2) & Total n 4941 & OR & OR 95\% Cl \\
\hline \multicolumn{5}{|c|}{ Participating in sports during the week } \\
\hline No & $29(3.3)$ & 872 & 1.00 (ref) & 1.00 (ref) \\
\hline Yes & $129(3.2)$ & 4069 & 0.95 & $1.03(0.67-1.58)$ \\
\hline \multicolumn{5}{|c|}{ Sports activity: number of days per week } \\
\hline 0 & $29(3.3)$ & 872 & 1.00 (ref) & 1.00 (ref) \\
\hline 1 & $29(2.6)$ & 1116 & 0.78 & $1.26(0.60-2.65)$ \\
\hline 2 & $51(3.3)$ & 1559 & 0.98 & $1.02(0.49-2.16)$ \\
\hline 3 & $36(3.8)$ & 947 & 1.15 & $1.37(0.68-2.75)$ \\
\hline$\geq 4$ & $13(2.9)$ & 447 & 0.87 & $1.63(0.80-3.35)$ \\
\hline \multicolumn{5}{|c|}{ Outdoor activity: hours per week } \\
\hline $0-3$ & $23(2.8)$ & 812 & 1.00 (ref) & 1.00 (ref) \\
\hline $4-6$ & $37(3.2)$ & 1162 & 1.13 & $1.01(0.59-1.74)$ \\
\hline $7-13$ & $55(3.2)$ & 1704 & 1.14 & $1.02(0.61-1.70)$ \\
\hline $14-20$ & $27(3.3)$ & 830 & 1.15 & $0.93(0.52-1.67)$ \\
\hline $21-60$ & $7(3.4)$ & 207 & 1.20 & $0.88(0.35-2.22)$ \\
\hline \multicolumn{5}{|c|}{ Children with very low level physical activity levels } \\
\hline Yes & $6(2.4)$ & 247 & 1.00 (ref) & 1.00 (ref) \\
\hline No & $152(3.2)$ & 4694 & 1.34 & $1.36(0.59-3.2)$ \\
\hline \multicolumn{5}{|c|}{ Sedentary activities: hours per week ${ }^{b}$} \\
\hline $0-7$ & $14(2.5)$ & 569 & 1.00 (ref) & 1.00 (ref) \\
\hline $8-14$ & $73(3.5)$ & 2083 & 1.44 & $1.35(0.74-2.49)$ \\
\hline $15-21$ & $50(3.5)$ & 1412 & 1.46 & $1.38(0.73-2.62)$ \\
\hline $22-28$ & $11(2.0)$ & 549 & 0.81 & $0.68(0.30-1.57)$ \\
\hline $29+$ & $6(2.6)$ & 233 & 1.05 & $0.81(0.28-2.36)$ \\
\hline
\end{tabular}

a Total differs due to missing values

${ }^{\mathrm{b}}$ Watching television, using a computer, playing video games and reading books and comics

OR Odds ratio, $\mathrm{Cl}$ Confidence interval 
morbidity observed in this newborn population [9]. However, moderately preterm infants account for $80 \%$ of premature births [17]. Therefore, it is important to focus on this large group, particularly because there is increasing evidence that these patients are also at increased risk for developmental and behavioural morbidities $[17,18]$. To the best of our knowledge, our study is the first to investigate a group of moderately preterm infants regarding leisure time physical activity.. By excluding multiple births and all children with handicaps that may influence their ability related to physical activity our results can only be generalized to singletons without a moderate to severe physical handicap born moderately preterm.

Our moderately preterm population had a significantly higher prevalence of asthma (19\%) than children born at term $(8.3 \%)$, which has also been demonstrated in other populations [40]. However, there was no difference in the amount of time spent engaged in physical activity. One explanation may be that the parents of children born preterm who suffer from asthma may be more motivated to enrol their child in sports activities. Another reason could be that most Danish children have well controlled asthma or that parents with children born preterm reported that their children suffer from asthma more often than other parents. The results of our subanalysis demonstrated that the results remained essentially unchanged after excluding children diagnosed with asthma.

We conducted a population-based cohort study using prospective data from a single prenatal care setting and obstetrics department in the second largest city in Denmark, where prenatal care and hospital delivery are free of charge; therefore, the cohort represents all socio-demographic groups. We excluded children with severe mental and physical health problem, twins and triplets to enhance comparability between the two groups of children. A selfadministered questionnaire was used to collect information about the children's physical activities; this could potentially introduce inaccuracy. The questionnaire used to assess physical activity resulted in a mere description of duration and type of leisure time activity rather than intensity. The type and duration should be simple for parents to reconstruct since many children attend sports on specific weekdays for a well-defined number of hours that the parents will pay for. Differential misclassification of children's physical activity would impact our results. However, we have no reason to believe that parents of preterm children would report their activity differently than parents of children born at term. Another way to measure physical activity is with an objective form of measurement, such as an accelerometer, as seen elsewhere [9]. Objective measurements may introduce selection biases into the study due to compliance problems while obtaining measurements or due to a lack of willingness to participate in the assessment. The care of children born after 32 weeks has essentially remained unchanged over the last decades. Accordingly, we believe that our results may be extrapolated to more recent time.

The fraction of moderately preterm children was similar in children followed up to that among children lost to follow up (3.2\% vs $4.2 \%)$. However, if the families with more physical active children were more prone to participate if the child was preterm than if they were term, this may have introduced bias towards a more favorable physical profile for preterm compared to term children. However, we consider this explanation for our results unlikely.

The proportion of healthy children born moderately preterm among participants is comparable to the proportion of preterm delivery in the Danish national birth register at that time [41]. This indicates that selection biases may not be a major issue. The overall rate of preterm delivery in Denmark is rather low compared to other industrialized countries such as United States [42]. However, we have no reason to believe that the results of this study cannot be found in populations in other countries.

Physical inactivity is associated with a higher risk of obesity, and children and adolescents are becoming more sedentary $[21,22]$. It may be even more important for infants born preterm to follow the guidelines for physical activity, as studies have indicated that preterm delivery is associated with a higher risk of stroke [43] and type 2 diabetes [24] in adulthood. These diseases are associated with lower levels of physical activity, and there is evidence that physical activity may prevent them $[21,22]$.

\section{Conclusions}

In this study of 9- to 11-year-old children, we found no differences in leisure time activities as weekly number of sports activities outside school, hours spent on outdoor activity and hours spent on sedentary activity between children born moderately preterm and children born at term. This finding is reassuring as physical activity is a fundamental element of a normal childhood and is important for longterm development [44]. Only one-third of school-aged children regardless of gestational age at birth in our study were as physically active as recommended by the national health guidelines for children [29]; thus, a focus on the factors that increase physical activity of all children is necessary. 


\section{Abbreviations}

Cl: Confidence intervals; LMP: Last menstrual period; OR: Odds Ratio; SD: Standard deviation

\section{Funding}

The Augustinus Foundation and the Lundbeck Foundation. The funding bodies had no influence on study design and have no role in data acquisition, data analyses and interpretation or manuscript preparation.

\section{Availability of data and materials}

Data are stored in the Perinatal Epidemiology Research Unit, Department of Paediatrics, Aarhus University Hospital, Aarhus and may not be distributed without permission from the Danish Data Protection Agency. For more information on how to access this data please contact the corresponding author.

\section{Authors' contributions}

MNL, HKH, MSL and TBH conceptualized the idea and design of the study. $\mathrm{TBH}, \mathrm{MH}, \mathrm{CO}$, and MSL were responsible for acquisition of data. MNL and $\mathrm{HKH}$ were responsible for data analyses and they drafted the first version of the manuscript. All authors have been involved in revising the manuscript critically for important intellectual content and have given final approval of the version to be published. In addition, all authors have agreed to be accountable for all aspects of the work in ensuring that questions related to the accuracy or integrity of any part of the work are appropriately investigated and resolved.

\section{Ethics approval and consent to participate}

The research protocol was approved by The Central Denmark Region Committees on Health Research Ethics (no. 1991/2060) and by the Danish Data Protection Agency (no 2012-41-1084) and (no 2007-41-0942). Participants were given written information about the study during pregnancy and the follow-up study when the offspring were 9 to 11 years old. Participants provided informed written consent to participate after completing the questionnaires.

\section{Competing interests}

The authors declare that they have no competing interests.

\section{Publisher's Note}

Springer Nature remains neutral with regard to jurisdictional claims in published maps and institutional affiliations.

\section{Author details}

'The Research Unit of Women's and Children's Health, section 7821, The Juliane Marie Centre, Copenhagen University Hospital, Rigshospitalet, Blegdamsvej 9, DK-2100 Copenhagen, Denmark. ${ }^{2}$ Faculty of Health and Medical Sciences, University of Copenhagen, Copenhagen, Denmark. ${ }^{3}$ Obstetric Clinic, The Juliane Marie Centre, Rigshospitalet, Copenhagen University Hospital, Copenhagen, Denmark. ${ }^{4}$ Child, Family and Reproductive Health, Department of Health Science, Faculty of Medicine, Lund University, Lund, Sweden. ${ }^{5}$ Institute of General Medical Practice, Department of Public Health, Aarhus University, Aarhus, Denmark. ${ }^{6}$ Perinatal Epidemiology Research Unit, Department of Paediatrics, Aarhus University Hospital, Skejby, Aarhus, Denmark.

\section{Received: 18 March 2016 Accepted: 3 May 2018}

\section{Published online: 12 May 2018}

\section{References}

1. WHO: recommended definitions, terminology and format for statistical tables related to the perinatal period and use of a new certificate for cause of perinatal deaths. Modifications recommended by FIGO as amended October 14, 1976. Acta Obstet Gynecol Scand. 1977;56:247-53.

2. Slattery MM, Morrison JJ. Preterm delivery. Lancet. 2002;360:1489-97.

3. Anderson P, Doyle LW. Neurobehavioral outcomes of school-age children born extremely low birth weight or very preterm in the 1990s. JAMA. 2003: 289:3264-72.

4. Moss TJ. Respiratory consequences of preterm birth. Clin Exp Pharmacol Physiol. 2006;33:280-4.
5. Taylor HG, Minich NM, Klein N, Hack M. Longitudinal outcomes of very low birth weight: neuropsychological findings. J Int Neuropsychol Soc. 2004;10: 149-63.

6. Hack M, Flannery DJ, Schluchter M, Cartar L, Borawski E, Klein N. Outcomes in young adulthood for very-low-birth-weight infants. N Engl J Med. 2002; 346:149-57.

7. Moster D, Lie RT, Markestad T. Long-term medical and social consequences of preterm birth. N Engl J Med. 2008;359:262-73.

8. Wilson-Costello D, Friedman H, Minich N, Fanaroff AA, Hack M. Improved survival rates with increased neurodevelopmental disability for extremely low birth weight infants in the 1990s. Pediatrics. 2005;115:997-1003.

9. Welsh L, Kirkby J, Lum S, Odendaal D, Marlow N, Derrick G, et al. The EPICure study: maximal exercise and physical activity in school children born extremely preterm. Thorax. 2010;65:165-72

10. Ekeus C, Lindstrom K, Lindblad F, Rasmussen F, Hjern A. Preterm birth, socia disadvantage, and cognitive competence in Swedish 18- to 19-year-old men. Pediatrics. 2010;125:e67-73.

11. Hille ET, den Ouden AL, Saigal S, Wolke D, Lambert M, Whitaker A, et al. Behavioural problems in children who weigh $1000 \mathrm{~g}$ or less at birth in four countries. Lancet. 2001;357:1641-3.

12. Bhutta AT, Cleves MA, Casey PH, Cradock MM, Anand KJ. Cognitive and behavioral outcomes of school-aged children who were born preterm: a meta-analysis. JAMA. 2002;288:728-37.

13. Saigal $S$, den OL, Wolke D, Hoult L, Paneth N, Streiner DL, et al. School-age outcomes in children who were extremely low birth weight from four international population-based cohorts. Pediatrics. 2003;112:943-50.

14. Hack M, Taylor HG, Drotar D, Schluchter M, Cartar L, Andreias L, et al. Chronic conditions, functional limitations, and special health care needs of school-aged children born with extremely low-birth-weight in the 1990s. JAMA. 2005:294:318-25.

15. Litt J, Taylor HG, Klein N, Hack M. Learning disabilities in children with very low birthweight: prevalence, neuropsychological correlates, and educational interventions. J Learn Disabil. 2005;38:130-41.

16. Marlow N, Wolke D, Bracewell MA, Samara M. Neurologic and developmental disability at six years of age after extremely preterm birth. N Engl J Med. 2005;352:9-19.

17. Vohr B. Long-term outcomes of moderately preterm, late preterm, and early term infants. Clin Perinatol. 2013:40:739-51.

18. McGowan JE, Alderdice FA, Holmes VA, Johnston L. Early childhood development of late-preterm infants: a systematic review. Pediatrics. 2011; 127:1111-24.

19. Kajantie E, Strang-Karlsson S, Hovi P, Raikkonen K, Pesonen AK, Heinonen K, et al. Adults born at very low birth weight exercise less than their peers born at term. J Pediatr. 2010;157:610-6. 616

20. Kaseva N, Wehkalampi K, Strang-Karlsson S, Salonen M, Pesonen AK, Raikkonen $\mathrm{K}$, et al. Lower conditioning leisure-time physical activity in young adults born preterm at very low birth weight. PLoS One. 2012;7: e32430.

21. Hu FB. Sedentary lifestyle and risk of obesity and type 2 diabetes. Lipids. 2003;38:103-8.

22. Pedersen BK: Fysisk aktivitet - håndbog om forebyggelse og behandling. 2003

23. Doyle LW, Faber B, Callanan C, Morley R. Blood pressure in late adolescence and very low birth weight. Pediatrics. 2003;111:252-7.

24. Kaijser M, Bonamy AK, Akre O, Cnattingius S, Granath F, Norman M, et al. Perinatal risk factors for diabetes in later life. Diabetes. 2009;58:523-6.

25. Hofman $\mathrm{PL}$, Regan $\mathrm{F}$, Jackson $\mathrm{WE}$, Jefferies $\mathrm{C}$, Knight $\mathrm{DB}$, Robinson $\mathrm{EM}$, et al. Premature birth and later insulin resistance. N Engl J Med. 2004; 351:2179-86.

26. Hovi P, Andersson S, Jarvenpaa AL, Eriksson JG, Strang-Karlsson S, Kajantie E, et al. Decreased bone mineral density in adults born with very low birth weight: a cohort study. PLoS Med. 2009;6:e1000135.

27. Laaksonen DE, Lakka HM, Lynch J, Lakka TA, Niskanen L, Rauramaa R, et al. Cardiorespiratory fitness and vigorous leisure-time physical activity modify the association of small size at birth with the metabolic syndrome. Diabetes Care. 2003:26:2156-64

28. Telama R, Yang X, Viikari J, Valimaki I, Wanne O, Raitakari O. Physical activity from childhood to adulthood: a 21-year tracking study. Am J Prev Med. 2005;28:267-73.

29. SST. Anbefalinger om fysisk aktivitet til børn og unge (5-17 år). 2004. Ref Type: Online Source. 
30. Larsen PS, Kamper-Jorgensen M, Adamson A, Barros H, Bonde JP, Brescianin $S$, et al. Pregnancy and birth cohort resources in europe: a large opportunity for aetiological child health research. Paediatr Perinat Epidemiol. 2013;27: 393-414.

31. http://dda.dk/catalogue/9185?lang=en Ref Type: Online Source.

32. Pedersen CB, Gotzsche H, Moller JO, Mortensen PB. The Danish civil registration system. A cohort of eight million persons. Dan Med Bull. 2006; 53:441-9.

33. Hedegaard M, Henriksen TB, Sabroe S, Secher NJ. Psychological distress in pregnancy and preterm delivery. BMJ. 1993;307:234-9.

34. Dahan-Oliel N, Mazer B, Majnemer A. Preterm birth and leisure participation: a synthesis of the literature. Res Dev Disabil. 2012;33:1211-20.

35. Keller H, Bar-Or O, Kriemler S, Ayub BV, Saigal S. Anaerobic performance in 5- to 7-yr-old children of low birthweight. Med Sci Sports Exerc. 2000;32: 278-83

36. Svien LR. Health-related fitness of seven- to 10-year-old children with histories of preterm birth. Pediatr Phys Ther. 2003;15:74-83.

37. Kriemler S, Keller H, Saigal S, Bar-Or O. Aerobic and lung performance in premature children with and without chronic lung disease of prematurity. Clin J Sport Med. 2005;15:349-55.

38. Clemm H, Roksund O, Thorsen E, Eide GE, Markestad T, Halvorsen T. Aerobic capacity and exercise performance in young people born extremely preterm. Pediatrics. 2012;129:e97-e105.

39. Saigal S, Stoskopf B, Boyle M, Paneth N, Pinelli J, Streiner D, et al. Comparison of current health, functional limitations, and health care use of young adults who were born with extremely low birth weight and normal birth weight. Pediatrics. 2007;119:e562-73.

40. Jaakkola JJ, Ahmed P, leromnimon A, Goepfert P, Laiou E, Quansah R, et al. Preterm delivery and asthma: a systematic review and meta-analysis. $J$ Allergy Clin Immunol. 2006;118:823-30.

41. Langhoff-Roos J, Kesmodel U, Jacobsson B, Rasmussen S, Vogel I. Spontaneous preterm delivery in primiparous women at low risk in Denmark: population based study. BMJ. 2006;332:937-9.

42. Denney JM, Culhane JF, Goldenberg RL: Prevention of preterm birth. Womens Health (Lond Engl ) 2008:4;625-38

43. Koupil I, Leon DA, Lithell HO. Length of gestation is associated with mortality from cerebrovascular disease. J Epidemiol Community Health. 2005;59:473-4

44. Waxman A. WHO global strategy on diet, physical activity and health. Food Nutr Bull. 2004;25:292-302.

Ready to submit your research? Choose BMC and benefit from:

- fast, convenient online submission

- thorough peer review by experienced researchers in your field

- rapid publication on acceptance

- support for research data, including large and complex data types

- gold Open Access which fosters wider collaboration and increased citations

- maximum visibility for your research: over $100 \mathrm{M}$ website views per year

At BMC, research is always in progress.

Learn more biomedcentral.com/submissions 